\title{
GOVERNANÇA CORPORATIVA: UMA ANÁLISE DA RELAÇÃO ENTRE O TURNOVER DA ADMINISTRAÇÃO E O DESEMPENHO ${ }^{1}$
}

\author{
Bárbara Siqueira da Silva \\ Danielle Gonçalves Silva \\ Bruna Camargos Avelino \\ Valéria Gama Fully Bressan ${ }^{2}$
}

\begin{abstract}
RESUMO
A governança corporativa é considerada um mecanismo que possui como objetivo o alinhamento entre as ações dos administradores e os interesses dos acionistas. Pesquisas realizadas no final da década de 1980 e início da década de 1990 identificaram que a relação entre a rotatividade dos executivos (turnover) e o desempenho da entidade pode ser considerada uma métrica para avaliar a eficiência de um sistema de governança corporativa. Essa métrica tem sido estudada em economias desenvolvidas, como Estados Unidos, Dinamarca e Japão, mas pouco abordada em países de economia considerada emergente. Diante disso, este estudo teve como objetivo verificar se o desempenho das empresas brasileiras de capital aberto influencia na probabilidade de turnover dos altos cargos da administração, tendo como foco as companhias listadas na B3 no período de 2012 a 2017. A amostra foi constituída por 87 empresas, e o modelo utilizado foi o de regressão logística. Os resultados apontaram coeficientes negativos e significativos para as variáveis Retorno do Patrimônio líquido, Retorno das ações e Propriedade familiar. Dessa forma, pôde-se concluir que o desempenho das companhias está inversamente relacionado à rotatividade dos executivos e que as empresas familiares apresentam menor rotatividade de seus administradores.
\end{abstract}

Palavras-chave: Turnover. Governança corporativa. Desempenho.

\section{CORPORATE GOVERNANCE: AN ANALYSIS OF THE RELATIONSHIP BETWEEN MANAGEMENT TURNOVER AND PERFORMANCE}

\begin{abstract}
Corporate governance is considered a mechanism that aims to align the actions of the managers with the interests of shareholders. Researches conducted in the late 1980s and early 1990s identified that the relationship between executive turnover and the entity's performance can be considered as a metric to assess the efficiency of a corporate governance system. This metric has been studied in developed economies as the United States, Denmark and Japan, but scarcely addressed in emerging economies. Therefore, this study aimed to verify whether the

\footnotetext{
${ }^{1}$ Como citar este artigo: SILVA, B. S. da et al. Governança corporativa: uma análise da relação entre o turnover da administração e o desempenho. ForScience, Formiga, v. 8, n. 2, e00772, jul./dez. 2020. DOI: 10.29069/forscience.2020v8n2.e772.

2Autor para correspondência: Valéria Gama Fully Bressan valeria.fully@gmail.com
} 
performance of Brazilian companies influences the probability of turnover of senior management positions, focusing on companies listed on the Brazilian Stock Exchange, from 2012 to 2017. The sample consisted of 87 companies and the analysis was based on logistic regressions. The results showed negative and significant coefficients for the variables Return on Equity, Return on Shares and Family Ownership. Thus, it can be concluded that the performance of companies is inversely related to the turnover of executives, and also that family businesses have lower turnover of their managers.

Keywords: Turnover. Corporate governance. Performance.

\section{INTRODUÇÃO}

A governança corporativa tem como objetivo alinhar as ações e as escolhas dos gerentes aos interesses dos sócios. Diante disso, a governança pode ser definida como um mecanismo pelo qual os acionistas asseguram que o conselho de administração monitora e implementa medidas que são capazes de reduzir os conflitos de agência (ARMSTRONG; GUAY; WEBER, 2010).

Com a evolução do mercado de capitais e o crescimento das companhias, os acionistas começaram a exercer um papel mais direcionado à análise dos resultados e à tomada de decisão de aplicação de recurso. Já os administradores focaram nas decisões empresariais e nas estratégias que poderiam maximizar o retorno dos negócios (DAVIS; THOMPSON, 1994). Considerando-se esse aspecto, a continuidade da administração à frente dos negócios está relacionada com sua capacidade de gerar resultados econômico-financeiros que atendam às expectativas dos acionistas (WEISBACH, 1988; HITT; IRELAND; HOSKISSON, 2012). Quando isso não ocorre, ou seja, quando a entidade não apresenta desempenho satisfatório, a probabilidade de que ocorra a troca da administração (turnover) aumenta (VIEIRA; MARTINS, 2018).

A mensuração do turnover, normalmente, leva em consideração os altos cargos da administração, tais como presidente do conselho de administração, Chief Executive Officer (CEO) e outros diretores ou cargos do conselho de administração relevantes (WARNER; WATTS; WRUCK, 1988; KAPLAN, 1994a). A substituição desses altos cargos é uma condição necessária para uma boa governança corporativa, pois a sensibilidade da alta rotatividade de gerentes ao desempenho é uma medida da qualidade dessa governança (KAPLAN, 1994a, 1994b; MURPHY, 1999; DAHYA; MCCONNELL; TRAVLOS, 2002; VOLPIN, 2002).

A rotatividade dos gestores e o desempenho da companhia podem ser tratados como uma evidência de que a governança corporativa está atingindo, ou não, seu objetivo principal 
(MIYAJIMA; OGAWA; SAITO, 2018). Esse argumento também foi enfatizado por Kaplan (1994a, 1994b) e Coffee Junior (1998), quando salientaram que uma forma eficaz de avaliar um sistema de governança corporativa seria analisar se a rotatividade dos executivos aumenta à medida que o desempenho da empresa diminui.

Estudos anteriores, como os de Kang e Shivdasani (1995), Lausten (2002), Maury (2006) e Miyajima, Ogawa e Saito (2018), identificaram em países com sistema de governança corporativa semelhante ao brasileiro, associação significativa entre a rotatividade dos executivos e o desempenho da entidade. No entanto, estes estudos foram realizados em países como Japão, Itália, Dinamarca e Finlândia, ou seja, todos considerados desenvolvidos.

Assim, este estudo busca ampliar o conhecimento sobre a temática em análise, em um cenário econômico diferente, considerado subdesenvolvido, mas que apresenta características de governança semelhantes às japonesas e às da Europa continental, tais como concentração de capital e presença relevante de empresas familiares. Diante disso, formulou-se a seguinte questão de pesquisa: Qual a influência do desempenho das companhias de capital aberto brasileiras na probabilidade de rotatividade dos gestores que ocupam altos cargos da administração? O objetivo desta pesquisa foi verificar se o desempenho das empresas brasileiras de capital aberto influencia na probabilidade de turnover dos altos cargos da administração.

Este estudo contribui com a literatura, pois considera a rotatividade não apenas do CEO, mas também de outros cargos da alta administração responsáveis por decisões estratégicas, tais como o presidente do conselho de administração, o vice-presidente do conselho de administração e o vice CEO. A métrica para mensurar o turnorver foi baseada no estudo de Volpin (2002), pois a estrutura de propriedade da Itália, país em que o estudo citado foi realizado, é semelhante à do Brasil, uma vez que apresenta fraca proteção legal de acionistas minoritários, aplicação ineficiente da lei, alta concentração de propriedade e presença de uma quantidade substancial de ações preferenciais. Além disso, este estudo verifica, em um mercado ainda considerado emergente, se as empresas têm aderido à prática de troca dos altos cargos da administração caso o desempenho não seja satisfatório.

As pesquisas de Kang e Shivdasani (1995), Lausten (2002), Maury (2006) e Miyajima, Ogawa e Saito (2018), além de focarem em países desenvolvidos, mensuraram a rotatividade apenas pelo cargo do CEO. De modo similar, o estudo de Vieira e Martins (2018), realizado com empresas brasileiras integrantes do IBrX100, teve como foco investigar a influência da estrutura do conselho de administração e do controle corporativo no turnover do CEO. Nesse sentido, esta pesquisa complementa a literatura nacional, por analisar o efeito do desempenho 
no turnover dos cargos do alto escalão, com o intuito de verificar se a governança corporativa brasileira segue os padrões dos países desenvolvidos.

\section{REFERENCIAL TEÓRICO}

Neste tópico, discutem-se as bases que serviram de direcionadores para a pesquisa, mais especificamente, são abordadas a governança corporativa e sua relação com a rotatividade dos gestores. Ademais, enumeram-se os estudos anteriores em cujo escopo os assuntos foram tratados.

\subsection{A relação entre a governança corporativa e a rotatividade dos gestores (turnover)}

Os conflitos de agência entre acionistas e gestores ou entre acionistas controladores e não controladores (minoritários) são conhecidos como as principais razões que fundamentaram o surgimento da governança corporativa (ANDRADE; ROSSETTI, 2012). O sistema de governança corporativa utilizado pelas empresas depende, geralmente, do ambiente em que elas estão inseridas (BIANCHI et al., 2009). De maneira geral, existem dois grandes modelos de governança corporativa, e os demais são derivados destes, que são: o Anglo-saxão e o da Europa continental (AHMAD; OMAR, 2016).

O modelo anglo-saxão é originário dos Estados Unidos e do Reino Unido e tem como premissa básica maximizar a riqueza dos acionistas, pois eles são os proprietários da corporação (SHLEIFER; VISHNY, 1997). O conselho de administração, normalmente, é mais independente, e o presidente do conselho não pode ser o diretor-presidente (MEIER; MEIER, 2014). Dessa forma, a propriedade é mais dispersa, e o principal conflito de agência ocorre entre a direção e os acionistas. Além disso, os membros independentes não devem se ater aos interesses de acionistas dominantes, e sim de todos os acionistas (LA PORTA; LOPEZ; SHLEIFER, 1999; COOMBES; WATSON, 2001).

O modelo da Europa continental, ao contrário do anglo-saxão, adota uma perspectiva mais ampla e acredita que a instituição deve salvaguardar interesses legítimos e não apenas os dos acionistas, ou seja, deve proteger diferentes grupos de stakeholders, tais como: clientes, fornecedores, governo e a sociedade em geral (MAASSEN, 1999). Neste modelo, os bancos detêm proporções significativas das ações e costumam ter controle e poder de decisão na instituição (CERNAT, 2004). O conselho de administração possui uma parcela independente, que é responsável pela supervisão dos membros do conselho e pelo monitoramento das decisões 
empresariais. Além disso, o modelo costuma apresentar propriedade mais concentrada nas mãos dos administradores e membros dos conselhos, bem como pode apresentar conflitos de agência entre acionistas majoritários e minoritários (BHASA, 2004; HOPT; LEYENS, 2004).

Segundo Silveira (2004), o modelo de governança corporativa utilizado no Brasil assemelha-se ao da Europa Continental. Isto ocorre porque, no mercado de capitais brasileiro, há concentração de capital, empresas familiares, conflito de agência entre acionistas majoritários e minoritários e sobreposição entre propriedade e gestão (ANDRADE; ROSSETTI, 2012).

Contudo, Silva e Grzybovski (2006) enfatizam que, independentemente do sistema de governança corporativa adotado, ele seria o reflexo da qualidade da gestão da empresa. Nesse sentido, Brickley e Zimmerman (2010) destacam que um sistema de governança envolve múltiplos componentes (estrutura do conselho, estrutura de remuneração, auditores, contratos de dívida, regulamentação governamental etc.), e a avaliação da qualidade da governança não depende apenas de um dos seus componentes, mas do sistema como um todo.

Considerando-se esse aspecto, pesquisas com as de Shleifer e Vishny (1986), McConnell e Servaes (1990) e Kaplan (1994a, 1994b) apresentaram duas medidas diferentes para avaliar a eficiência de um sistema de governança corporativa. A primeira métrica está relacionada ao benchmarking, ou seja, comparar o desempenho da companhia com o de seus concorrentes (SHLEIFER; VISHNY, 1986; MCCONNELL; SERVAES, 1990). Já a segunda seria analisar se a rotatividade dos executivos está relacionada com o desempenho da empresa (KAPLAN, 1994a). De acordo com Kaplan (1997), desconsiderando-se as aparentes diferenças entre os modelos de governança corporativa, os altos executivos enfrentam o mesmo risco de rotatividade caso a empresa apresente queda ou mau desempenho.

Na pesquisa de Kaplan (1994a), o autor objetivou identificar a relação entre a alta rotatividade, a remuneração dos executivos e o desempenho apresentado pelas empresas japonesas e americanas. Constatou-se que tanto a rotatividade quanto a remuneração dos executivos estavam relacionadas com os ganhos, com os retornos das ações e, em menor escala, com as métricas de desempenho das vendas. Diante disso, observou-se que as riquezas dos executivos estavam positivamente correlacionadas ao desempenho das ações e aos fatores que contribuíam para o desempenho da entidade.

A importância da utilização de medidas de desempenho da entidade como métrica de avaliação de performance dos gestores é intrínseca ao princípio da informatividade de Hölmstrom (1979). Em suma, esse princípio considera que índices econômico-financeiros podem refletir as consequências das tomadas de decisões dos administradores. Além disso, 
qualquer informação adicional aos índices contábeis também seria capaz de evidenciar os esforços dos agentes em maximizar o valor da empresa.

Estudos sobre essa temática já foram realizados em distintos países do mundo, podendose constatar que tanto as variações nos preços das ações quanto o desempenho econômicofinanceiro estão negativamente relacionados à alta rotatividade da administração. Essas métricas se mostram relevantes, pois os preços das ações e o desempenho são, na literatura, as principais medidas de interesse dos acionistas, visto que mensuram a variabilidade dos ativos e como eles estão sendo salvaguardados (KAPLAN, 1994a, 1994b; DENIS; KRUSE, 2000; CONYON; FLOROU, 2002; FEE; HADLOCK, 2004; FALEYE, 2007). Ademais, se as medidas para avaliar a eficiência do sistema de governança corporativa forem eficientes, pode ser encontrada uma relação negativa entre a rotatividade dos administradores e as variações nos preços das ações (WARNER; WATTS; WRUCK, 1988).

Conyon e He (2014) argumentam que os preços das ações podem oscilar por motivos inerentes ao mercado, ou seja, variações nos preços destas podem não representar o melhor meio para se analisar o desempenho dos gestores. Por isso, o desempenho contábil seria uma métrica que melhor refletiria os impactos da gestão dos administradores.

De acordo com Hazarika, Karpoff e Nathata (2012), os executivos podem vir a gerenciar os resultados com foco no aumento da sua remuneração e nos possíveis ganhos com retornos das ações, objetivando estabilidade no emprego. Essas medidas poderiam elevar os custos dos acionistas, e, por isso, os controles internos e outras medidas de governança corporativa seriam os disciplinadores para os gestores não realizarem atividades que beneficiariam seu próprio interesse. No estudo realizado por Hazarika, Karpoff e Nathata (2012), observou-se que o gerenciamento de resultados aumenta a probabilidade da rotatividade dos CEOs e está negativamente associado ao período de vigência do mandato do profissional.

\subsection{Estudos anteriores}

Kang e Shivdasani (1995) analisaram o papel dos mecanismos de governança corporativa durante a alta rotatividade de executivos nas corporações japonesas. O sistema bancário do Japão desempenha um papel importante na governança corporativa e disciplina os gerentes corporativos em caso de desempenho ruim. Dessa forma, usando dados de 270 empresas japonesas de 1985 a 1990, foram examinados os efeitos dos principais bancos e diretores externos sobre a relação entre a alta rotatividade de executivos e o desempenho das empresas. Os resultados indicaram a probabilidade de a rotatividade estar significativamente 
relacionada ao retorno dos ativos, ao excesso de retornos das ações e à receita operacional negativa, não estando, porém, relacionada ao desempenho do setor no qual a empresa estava inserida. Observou-se, também, que a sensibilidade da rotatividade em relação ao desempenho dos lucros é maior para as empresas com ligações a um banco do que para aquelas sem esses laços, e que a sucessão externa, no Japão, é mais provável para organizações com grandes acionistas e relacionadas a uma instituição bancária.

Volpin (2002) estudou os determinantes da rotatividade de executivos e da avaliação das empresas em função da estrutura de propriedade e controle na Itália, um país que apresenta baixa proteção legal para investidores, empresas com acionistas controladores e grupos piramidais. A amostra foi constituída por 205 empresas listadas na Bolsa de Milão. Os resultados sugerem que há uma má governança, medida por uma baixa sensibilidade do turnover ao desempenho e uma baixa relação do índice $\mathrm{Q}$ da firma (valor de mercado da empresa sobre o valor contábil do ativo total) quando: (i) os acionistas controladores também são altos executivos; (ii) o controle está totalmente nas mãos de um acionista e não é compartilhado por um conjunto de acionistas principais; e (iii) os acionistas controladores detêm menos de $50 \%$ dos direitos de fluxo de caixa da empresa.

Lausten (2002) examinou se existia uma relação entre a substituição do CEO e o desempenho corporativo das empresas dinamarquesas. A principal hipótese testada era se a probabilidade de rotatividade do CEO estava inversamente relacionada ao desempenho da empresa. A amostra da pesquisa foi constituída por grandes e médias empresas dinamarquesas no período de 1992 a 1995. Os resultados encontrados mostraram que a ameaça ao volume de negócios garante que o CEO atue no interesse dos acionistas. Além disso, o status de presidente do conselho e os laços familiares dentro da administração e propriedade da empresa fortalecem o relacionamento entre a rotatividade do CEO e o desempenho da companhia.

Maury (2006) investigou como a governança corporativa e o desempenho das empresas afetavam a alta rotatividade de executivos. A amostra do estudo foi constituída por empresas finlandesas no período de 1993 a 2000. Os resultados indicaram um aumento na rotatividade dos CEOs na alta administração e no giro do conselho, em resposta ao desempenho precário do preço das ações e das perdas operacionais. Verificou-se, também, que a sensibilidade da relação entre o desempenho do preço das ações e a rotatividade dos CEO será significativamente maior em empresas com estrutura de dois níveis (quando o CEO não é o presidente), mas consideravelmente menor quando o CEO ou membro do conselho era o acionista controlador. Esses resultados sugerem que tanto a estrutura de propriedade quanto o design do conselho têm implicações para o disciplinamento dos gerentes.

ForScience, Formiga, v. 8, n. 2, e00772 jul./dez. 2020. 
Miyajima, Ogawa e Saito (2018) examinaram a rotatividade de altos executivos em firmas japonesas durante o período de 1990 a 2013. Durante esse intervalo, um banco foi enfraquecido, a propriedade de investidores institucionais aumentou rapidamente e foram introduzidos diretores externos independentes em muitas empresas. Neste contexto, os resultados indicaram que a sensibilidade da alta rotatividade dos executivos ao desempenho corporativo não mudou, apesar do ceticismo quanto ao governo corporativo das empresas japonesas. Por outro lado, houve uma mudança no retorno sobre os ativos (ROA), no retorno sobre o patrimônio líquido (ROE) e nos retornos das ações. Os investidores institucionais estrangeiros fortaleceram a sensibilidade do volume de negócios ao ROE após a crise bancária, quando sua participação aumentou drasticamente. Por outro lado, não houve indícios de que diretores externos independentes tenham qualquer efeito significativo para aumentar a sensibilidade do volume de negócios ao ROE. Os fortes laços com os bancos indicaram que eles ainda continuam desempenhando um papel disciplinador.

Vieira e Martins (2018), por fim, analisaram a influência da estrutura do conselho de administração e do controle corporativo no turnover do CEO das empresas abertas no Brasil. A amostra reuniu 111 empresas integrantes do índice IBrX100 da B3 entre os anos de 2009 a 2013. Os resultados apontaram que as chances de ocorrência de turnover do CEO aumentam quando a empresa apresenta baixo retorno acionário e/ou lucratividade. A independência do Conselho não influenciou a sensibilidade do turnover do $\mathrm{CEO}$ ao desempenho. Outros resultados indicaram que a dualidade dos cargos de CEO e Chairman estava negativamente relacionada ao turnover do CEO. Já a concentração acionária, levando-se em consideração as ações totais, diminuiu a sensibilidade do turnover do CEO ao desempenho.

\section{MATERIAL E MÉTODOS}

Segundo conceitos abordados por Martins e Theóphilo (2009), com relação à abordagem do problema, esta pesquisa foi classificada como quantitativa, visto que o uso da estatística inferencial foi fundamental para responder o problema de pesquisa proposto. No que tange aos objetivos, considerando-se que o foco do estudo foi identificar qual a influência do desempenho das empresas na probabilidade de rotatividade dos gestores, de acordo com a definição de Vergara (2014), esta pesquisa pode ser classificada como descritiva.

A pesquisa bibliográfica e a documental foram as estratégias de pesquisa escolhidas para este estudo. Baseando-se nas definições de Martins e Theóphilo (2009), a pesquisa bibliográfica proporcionou encontrar, em materiais já publicados, conhecimento sobre o tema 
abordado; e a pesquisa documental foi fundamental para este estudo, visto que foram realizadas consultas no Formulário de Referência (documento obrigatório anual que as companhias de capital aberto devem fornecer à Comissão de Valores Mobiliários - CVM).

Por volta dos anos 2000, a Bolsa de Valores de São Paulo (atualmente conhecida como B3) criou o Novo Mercado, um segmento de listagem para companhias que publicassem voluntariamente práticas adicionais de governança corporativa. $\mathrm{O}$ objetivo era reduzir a assimetria informacional existente entre os acionistas e os executivos, bem como estimular a captação de recurso (MOREIRAS; TAMBOSI FILHO; GARCIA, 2010). Esse segmento estabelece um padrão de governança corporativa altamente diferenciado - o Novo Mercado “tornou-se o padrão de transparência e governança exigido pelos investidores para as novas aberturas de capital, sendo recomendado para empresas que pretendam realizar ofertas direcionadas a qualquer tipo de investidor" (B3, 2018, p. 01).

Considerando-se a relação desse segmento com o objeto de estudo desta pesquisa, a amostra deste estudo foi constituída pelas empresas classificadas no Novo Mercado da B3, englobando o período de 2012 a 2017, com exceção das instituições financeiras, que apresentam demonstrações contábeis diferenciadas dos demais segmentos, o que totalizou 87 companhias. Este período foi escolhido tendo em vista o fato de que, em 2011, foi alterado o regulamento e os critérios para enquadramento no Novo Mercado. Dessa forma, foi adotado o intervalo entre 2012 e 2017 porque a norma se manteve a mesma, proporcionando maior nível de comparabilidade entre os itens amostrados.

A variável dependente turnover e a variável de controle "familiar" foram obtidas por meio de consulta ao Relatório de Referência, encontrado no site da Comissão de Valores Mobiliários - CVM. Obtiveram-se as demais variáveis do modelo econométrico por meio da base de dados Economática®.

As variáveis do modelo estimado neste estudo foram selecionadas de acordo com a literatura nacional e internacional, conforme evidenciado no Quadro1.

A partir dos dados em painel, foram gerados três modelos para verificar qual se ajustava melhor aos dados e gerava as melhores estimativas, sendo eles: o Logit Efeitos Fixos- EF - e Efeitos Aleatórios - RE - e o LogitPooled, dado que este último foi empregado nos estudos de Maury (2006), Vieira e Martins (2018), Kang e Shivdasani (1995) e Volpin (2002). A rotatividade dos executivos é uma variável binária que recebe o valor 1 , no ano t, se pelo menos metade dos executivos de alto escalão (Presidente e vice, Presidente do Conselho de Administração e vice) é substituída entre t e $\mathrm{t}+1$. Tal proxy foi elaborada com base no trabalho de Volpin (2002), que inclui no grupo de executivos de alto escalão a diretoria e o Conselho de 
Administração. Segundo o autor, isso é preferível a considerar apenas a rotatividade de CEOs, uma vez que os executivos de alto escalão podem ter poder semelhante, não existindo uma classificação clara de autoridade entre eles. A proporção feita permite resolver questões como a dualidade do CEO, ou seja, a mesma pessoa ocupar o cargo de presidente e de presidente do Conselho, além da possibilidade de haver mais de um CEO. Logo, considerar todos os principais cargos do alto escalão e fazer uma proporção permite uma análise mais abrangente, visto que leva em conta os principais envolvidos na tomada de decisões.

\begin{tabular}{|c|c|c|c|c|c|}
\hline Variável & Sigla & Fórmula & Descrição & $\begin{array}{c}\text { Sinal } \\
\text { Esperado }\end{array}$ & Literatura \\
\hline \multicolumn{6}{|c|}{$\begin{array}{l}\text { Variável Dependente } \\
\end{array}$} \\
\hline Turnover & Turn & $\begin{array}{c}\text { Dummy: } \\
\text { Y= } 1 \text { - Houve troca de } 50 \% \text { ou } \\
\text { mais dos executivos (presidente } \\
\text { do Conselho de Administração e } \\
\text { vice, presidente e vice- } \\
\text { presidente); } \\
\text { Y=0 - caso contrário. } \\
\text { (parâmetro utilizado por Volpin } \\
\text { (2002) }\end{array}$ & $\begin{array}{r}\text { Trocas nos car } \\
\text { Diretoria e Cons } \\
\text { Administração - } n \\
\text { de } 2012 \text { a } 2017 . \mathbf{~} \\
\text { Quanto pior o dese } \\
\text { empresa, ma } \\
\text { probabilidade de ro }\end{array}$ & $\begin{array}{l}\text { gos de: } \\
\text { selho de } \\
\text { o período } \\
\text { Hipótese: } \\
\text { mpenho da } \\
\text { ior a } \\
\text { tatividade. }\end{array}$ & $\begin{array}{c}\text { Kaplan (1994a, } \\
\text { 1994b), Coffee Junior } \\
\text { (1998), Maury } \\
\text { (2006), Volpin (2002) } \\
\text { e Miyajima Ogawa e } \\
\text { Saito (2018). }\end{array}$ \\
\hline \multicolumn{6}{|c|}{ Variáveis Independentes } \\
\hline $\begin{array}{c}\text { Retorno } \\
\text { Sobre o } \\
\text { Ativo } \\
\end{array}$ & ROA & $(\mathrm{LO}+\mathrm{LNO} / \mathrm{ATM})^{*}$ & $\begin{array}{c}\text { Mede a } \\
\text { rentabilidade do } \\
\text { ativo total } \\
\end{array}$ & - & $\begin{array}{c}\text { Miyajima, Ogawa e } \\
\text { Saito (2018) e Kang e } \\
\text { Shivdasani (1995) }\end{array}$ \\
\hline $\begin{array}{c}\text { Retorno } \\
\text { sobre o } \\
\text { Patrimônio } \\
\text { Líquido }\end{array}$ & ROE & $(\mathrm{LL} / \mathrm{PLM})^{*}$ & $\begin{array}{l}\text { Mede a } \\
\text { rentabilidade do } \\
\text { Patrimônio } \\
\text { Líquido }\end{array}$ & - & $\begin{array}{l}\text { Miyajima, Ogawa e } \\
\text { Saito (2018) }\end{array}$ \\
\hline $\begin{array}{l}\text { Retorno } \\
\text { das Ações }\end{array}$ & RET & $((\mathrm{PF} 1-\mathrm{PFt}-1+\mathrm{DIVD}) / \mathrm{PFt}-1)^{*}$ & $\begin{array}{l}\text { Mede o Retorno } \\
\text { das Ações }\end{array}$ & - & $\begin{array}{l}\text { Miyajima, Ogawa e } \\
\text { Saito (2018), Maury } \\
\text { (2006) e Vieira e } \\
\text { Martins (2018) }\end{array}$ \\
\hline $\begin{array}{l}\text { Q de } \\
\text { Tobin }\end{array}$ & Q & $\begin{array}{c}(\mathrm{Q} \\
=(\mathrm{VMO}+\mathrm{VMAP}+\mathrm{DIVT}) / \mathrm{ATM})^{*}\end{array}$ & $\begin{array}{l}\text { Mede o Valor de } \\
\text { mercado da } \\
\text { Companhia }\end{array}$ & - & Maury (2006) \\
\hline \multicolumn{6}{|c|}{ Variáveis de Controle } \\
\hline Tamanho & Tam. & LnAtivo & $\begin{array}{l}\text { Quanto maior a } \\
\text { empresa, menor a } \\
\text { probabilidade de } \\
\text { rotatividade }\end{array}$ & - & Volpin (2002) \\
\hline Familiar & Fam & $\begin{array}{c}\text { Dummy: } 1 \text { - Relação familiar } \\
\text { com algum membro da } \\
\text { administração ou controlador; } 0 \text { - } \\
\text { Caso contrário }\end{array}$ & $\begin{array}{l}\text { A propriedade } \\
\text { familiar faz com } \\
\text { que a } \\
\text { probabilidade de } \\
\text { rotatividade } \\
\text { diminua. }\end{array}$ & - & $\begin{array}{c}\text { Volpin (2002), } \\
\text { Lausten (2002) e } \\
\text { Miyajima, Ogawa e } \\
\text { Saito }\end{array}$ \\
\hline
\end{tabular}

Quadro 1 - Variáveis do Modelo

Fonte: Autores (2018).

* Notas: LO - Lucro Operacional; LNO - Lucro não Operacional; ATM - Ativo Total Médio; LL - Lucro Líquido; PLM - Patrimônio Líquido Médio; PF1 - preço das ações no final do ano fiscal; PFt-1 - preço das ações no final do ano fiscal anterior; DIVD - dividendo por ação; VM - Valor de Mercado; DIVT - valor contábil das dívidas de curto e longo prazo menos o ativo circulante, após a exclusão do valor dos estoques. 
O modelo Logit permite estimar a probabilidade de ocorrência de um evento e identificar as variáveis independentes que contribuem para seu acontecimento. Os modelos gerados foram o LogitPooled (1) e o Logit de Efeitos Fixos e Aleatórios (2), para escolha do mais adequado.

$\ln \left(\frac{P(Y=1)}{P(Y=0)}\right)=\beta_{0}+\beta_{1} R O A_{i}+\beta_{2} R O E_{i}+\beta_{3} R E T_{i}+\beta_{4} Q_{i}+\beta_{5} T A M_{i}+\beta_{6} F A M_{i}+\eta_{i}$
$\ln \left(\frac{P_{i t}(Y=1)}{P_{i t}(Y=0)}\right)=\beta_{0}+\beta_{1} R O A_{i t}+\beta_{2} R O E_{i t}+\beta_{3} R E T_{i t}+\beta_{4} Q_{i t}+\beta_{5} T A M_{i t}+\beta_{6} F A M_{i t}+\varepsilon_{i t}+v_{i t}$

Nota: ln - é o logaritmo natural; $\eta$ - é o termo de erro do modelo LogitPooled; $\varepsilon$ - representa o efeito individual específico não observável e não varia com o tempo, no modelo logit em painel; v - diz respeito ao erro usual da regressão, o qual varia com o tempo.

A estimação do modelo é feita pelo método da máxima verossimilhança (WOOLDRIGDE, 2010). Estimam-se dois modelos para o logit em painel para verificar qual melhor se adequará aos dados. No logit em painel de Efeitos Fixos, o termo de erros, representado por $\varepsilon_{i t}$, possui correlação com as variáveis independentes, o que não ocorre no modelo de Efeitos Aleatórios. A especificação do modelo em painel é dada pelo teste de Hausman (WOOLDRIDGE, 2010). A hipótese nula do teste consiste em: os estimadores do modelo com Efeitos Aleatórios são os mais adequados por serem consistentes e eficientes; e a hipótese alternativa de que os estimadores de Efeitos Fixos são os mais adequados. A influência das variáveis explicativas sobre a probabilidade de ocorrer turnover dos executivos é dada pelo efeito marginal, que mede a variação da probabilidade de um evento ocorrer, ou seja, a chance de haver rotatividade dos cargos analisados dadas as alterações nas variáveis independentes.

\section{DISCUSSÃO DOS RESULTADOS}

A partir das variáveis extraídas da literatura, gerou-se a Matriz de Correlação de Person, conforme a Tabela 1. De acordo com Cohen (2013), correlações superiores a 0,5 são consideradas fortes. Dessa forma, espera-se que as variáveis dos modelos estimados apresentem baixa correlação. 
Tabela 1- Matriz de correlação

\begin{tabular}{lcccccc}
\hline \multicolumn{7}{c}{ Matriz de Correlação } \\
\hline ROA & ROA & ROE & RET & Q & TAM & FAM \\
ROE & 1 & $\mathbf{0 , 4 6 4}$ & 1 & & & \\
RET & $-0,0562$ & $-0,0322$ & 1 & & & \\
Q & $\mathbf{0 , 4 9 0}$ & 0,327 & 0,200 & 1 & & \\
TAM & $-0,184$ & $-0,193$ & 0,0557 & $-0,164$ & 1 & \\
FAM & $-0,0561$ & $-0,0595$ & 0,0388 & $-0,129$ & $-0,0760$ & 1 \\
\hline
\end{tabular}

Fonte: Dados da pesquisa.

Segundo a matriz de correlação, as variáveis ROA e ROE, Q-tobine ROA apresentam uma correlação mediana. Assim, para selecionar o conjunto de variáveis mais adequado, foram gerados três modelos LogitPooled: o primeiro com todas as variáveis, o segundo sem a variável ROA, e o terceiro sem as variáveis Q-tobin e ROA. A seleção do conjunto de variáveis que compõe o modelo final foi feita com base nos critérios de Akaike (AIC) e Informação Bayesiana (BIC). Dessa forma, optou-se pelo modelo LogitPooled 3, pois ele apresentou os menores valores para AIC e BIC, conforme a Tabela 2.

Tabela 2 - Modelos LogitPooled

\begin{tabular}{|c|c|c|c|c|c|c|}
\hline & & \multicolumn{5}{|c|}{ Modelos } \\
\hline \multirow[t]{2}{*}{ Variáveis } & \multicolumn{2}{|c|}{ LogitPooled 1} & \multicolumn{2}{|c|}{ LogitPooled 2} & \multicolumn{2}{|c|}{ LogitPooled 3} \\
\hline & Coef. & Std. Err. & Coef. & Std. Err. & Coef. & Std. Err. \\
\hline ROA & 0,00767 & $(1,1)$ & & & & \\
\hline ROE & $-0,0108 * *$ & $(2,65)$ & $-0,00607 *$ & $(2,00)$ & $-0,00626 *$ & $(2,37)$ \\
\hline RET & $-3,715 * * *$ & $(10,09)$ & $-3,771 * * *$ & $(10,27)$ & $-3,781 * * *$ & $(10,53)$ \\
\hline Q & $-0,1$ & $(0,80)$ & $-0,014$ & $(0,12)$ & & \\
\hline Tamanho & $-0,146$ & $(1,55)$ & $-0,159$ & $(1,70)$ & $-0,157$ & $(1,70)$ \\
\hline Familiar & $-0,4$ & $(1,70)$ & $-0,391$ & $(1,67)$ & $-0,385$ & $(1,68)$ \\
\hline Constante & $3,589 *$ & $(2,39)$ & $3,709 *$ & $(2,5)$ & $3,677 *$ & $(2,52)$ \\
\hline Número de observações & \multicolumn{2}{|c|}{522} & \multicolumn{2}{|c|}{522} & \multicolumn{2}{|c|}{522} \\
\hline AIC & \multicolumn{2}{|c|}{492,16} & \multicolumn{2}{|c|}{494,64} & \multicolumn{2}{|c|}{492,65} \\
\hline BIC & \multicolumn{2}{|c|}{521,96} & \multicolumn{2}{|c|}{520,19} & \multicolumn{2}{|c|}{513,94} \\
\hline
\end{tabular}

***significativa a $1 \%, * *$ significativa a $5 \%, *$ significativa a $10 \%$.

Fonte: Dados da pesquisa.

Após a retirada das variáveis correlacionadas e a escolha do modelo pelos critérios AIC e BIC, foram gerados os modelos de Efeitos Fixos e Aleatórios. De acordo com o teste de Hausman, o modelo de Efeitos Fixos é preferível ao modelo de Efeitos Aleatórios, no entanto, não há efeito marginal para tal modelo. Para a inferência sobre o efeito marginal, utilizaram-se os cálculos obtidos pelo modelo Pooled, com foco de análise apenas nas variáveis que foram estatisticamente significativas no modelo Logit_FE. Quanto ao ajuste dos dados, o modelo classificou corretamente 77,78\% destes. Para valores de $\mathrm{Y}=1$, o modelo acertou 85,67\%, e para $\mathrm{Y}=0,65,87 \%$, possuindo um bom ajuste. Tais informações encontram-se detalhadas na Tabela 3. 
Tabela 3 - Modelo Final - Pooled, Efeitos Aleatórios (RE) e Efeito Fixos (FE)

\begin{tabular}{|c|c|c|c|c|c|c|c|}
\hline & & & & Modelos & & & \\
\hline Variáveis & Efeito Marginal & LogitP & oled 3 & Logi & RE & Logit & FE \\
\hline & & Coef. & Std. Err. & Coef. & Std. Err. & Coef. & Std. Err. \\
\hline ROE & $-0,0015^{*}$ & $-0,00626^{*}$ & $(2,37)$ & $-0,00748 *$ & $(2,46)$ & $-0,0477 * * *$ & $(3,83)$ \\
\hline RET & $-0,8932 * * *$ & $-3,781 * * *$ & $(10,53)$ & $-3,942 * * *$ & $(10,02)$ & $-3,887 * * *$ & $(8,16)$ \\
\hline Tamanho & $-0,0371 * *$ & $-0,157 * *$ & $(1,70)$ & $-0,180$ & $(1,62)$ & 0,531 & $(0,74)$ \\
\hline Familiar & $-0,0913 * *$ & $-0,385^{* *}$ & $(1,68)$ & $-0,476^{* *}$ & $(1,71)$ & $-2,341 *$ & $(2,17)$ \\
\hline Constante & & $3,677 *$ & $(2,52)$ & $4,192 *$ & $(2,37)$ & & \\
\hline Número de obse & ções & 52 & & & & 46 & \\
\hline Número de grup & & & & & & 77 & \\
\hline $\mathrm{R}^{2}$ de $\mathrm{McF} F \mathrm{dde}$ & & 0,3 & & & & & \\
\hline Sensibilidade (c & $\mathrm{ff} 0,5)$ & 85,6 & & & & & \\
\hline Especificidade & off 0,5$)$ & 65,8 & & & & & \\
\hline Ajuste geral do & delo & 77,7 & & & & & \\
\hline Areaunder ROC & & 0,8 & & & & & \\
\hline Teste de Hausm & & $\chi^{2}=1$ & 7,37 & & alor $\mathrm{p}=0,0$ & & \\
\hline Insig2u & & & & & & $-0,91$ & \\
\hline sigma_u & & & & & & 0,63 & \\
\hline Rho & & & & & & 0,10 & \\
\hline
\end{tabular}

Fonte: Dados da pesquisa.

De maneira geral, os modelos estão de acordo com o esperado, pois todos os coeficientes e o efeito marginal possuem uma relação negativa com a rotatividade dos gestores. Desse modo, eles estão conforme a literatura, ou seja, a rotatividade está negativamente relacionada ao desempenho. Este estudo corrobora os achados das pesquisas de Laustem (2002), Volpin (2002), Miyajima, Ogawa e Saito (2018) e Vieira e Martins (2018).

As variáveis ROE e RET apresentaram o efeito marginal negativo e significativo, portanto, aumentando-se o valor do ROE ou do retorno das ações, reduz-se a probabilidade de troca dos gestores. Este resultado está em conformidade com os achados de Miyajima, Ogawa e Saito (2018) e Vieira e Martins (2018).

Segundo Lausten (2012) e Miyajima, Ogawa e Saito (2018) o ROE e o RET com coeficientes negativos e significativos estão relacionados com a teoria do principal e do agente, em que a ameaça de rotatividade garante que os gestores atuem no interesse dos acionistas. Considerando-se que o turnover, de acordo com Kaplan (1994a, 1994b) e Coffee Junior (1998), é uma métrica de governança corporativa e que a troca de gestores é uma condição necessária para a boa governança, pode-se concluir que as empresas do Novo Mercado da B3 estão adotando as medidas necessárias. Diante disso, quando a empresa não apresenta um bom resultado, há troca dos gestores, conforme indicado pelas boas práticas de governança. No entanto, segundo Conyon e He (2014), os preços das ações podem oscilar por motivos inerentes ao mercado, ou seja, não relacionados aos gestores. Assim, além do desempenho de mercado, 
é necessário analisar o desempenho contábil para se tomar alguma decisão em relação à troca ou não dos gestores.

Apesar de o segmento do Novo Mercado buscar atingir os padrões mais altos de governança corporativa, o mercado brasileiro é marcado pela alta concentração de propriedade, pela sobreposição entre gestão e propriedade, por conflitos de agência entre acionistas majoritários e minoritários e pela fraca proteção legal destes últimos. Diante desse cenário, o emprego de medidas adequadas de governança, como o turnover dos executivos (presidente ou presidente do conselho) quando o desempenho é ruim, pode não ocorrer. Afinal, poucos acionistas possuem poder de decisão, visto que há uma grande circulação de ações preferenciais. Além disso, o dono da empresa ou os membros de sua família, muitas vezes, ocupam os cargos mais altos da administração, fazendo com que dificilmente sejam destituídos. Sabendo-se que essa substituição nos cargos do alto escalão é um indicativo de boa governança, os acionistas e os investidores podem incluir essa análise em seus processos decisórios e, assim, investirem em empresas que tomam decisões racionais e impessoais, visando ao melhor resultado.

Em relação às variáveis de controle, o Tamanho da empresa não foi significativo no modelo de Efeitos Fixos e apresentou significância estatística a 10\% no modelo Pooled. Dessa forma, devido à contradição dos resultados, a variável foi considerada como não significativa, para evitar conclusões equivocadas. Já a relação familiar entre os gestores apresentou coeficientes negativos e significativos a $10 \%$. Portanto, a probabilidade de mudança nos cargos da administração em empresas familiares é menor. Este resultado está de acordo com as pesquisas de Lausten (2002), Volpin (2002) e Miyajima, Ogawa e Saito (2018).

Além do desempenho financeiro, outro fator que influencia na questão da rotatividade dos gestores é a estrutura de propriedade. De acordo com La Porta et al. (1997), mercados emergentes, como o Brasil, exibem uma menor competitividade, e as empresas apresentam maior concentração de capital, principalmente em firmas com relações familiares. Consequentemente, a governança em empresas familiares se dá com base em uma racionalidade permeada por regras e normas do sistema familiar, ou seja, é influenciada por sentimentos individuais e coletivos inerentes àquela família (BORNHOLDT, 2000). Para Schulze et al. (2001), a comunicação, a tomada de decisão e a supervisão dos administradores incorrem em menores custos e são facilitadas pelo fato de os membros terem conhecimento íntimo entre si. Além disso, desencorajam o desempenho ruim por haver essa relação próxima entre os integrantes da administração e destes com a firma. 
Portanto, os resultados encontrados nesta pesquisa estão de acordo com os achados nacionais e internacionais. O sistema de governança brasileiro, quando medido pelo critério de Kaplan (1994a, 1994b) e Coffee Junior (1998), pode ser considerado eficiente, visto que penaliza os executivos das empresas que possuem desempenho ruim. Se fosse verificada ausência de sensibilidade da rotatividade ao desempenho, isso indicaria uma estrutura de governança inadequada. No entanto, para analisar o turnover das firmas, deve-se levar em consideração a estrutura de propriedade destas, ou seja, se é familiar ou não, se possui concentração de capital e fatores inerentes ao mercado.

\section{CONSIDERAÇÕES FINAIS}

A governança é vista como um subconjunto de contratos no mundo corporativo e possui como objetivo alinhar quaisquer interesses divergentes entre os administradores e os sócios. É por meio da governança corporativa que os acionistas certificam-se que medidas de monitoramento estão sendo tomadas para reduzir provável conflito de agência. Tanto a rotatividade dos gestores em seus respectivos cargos quanto o desempenho econômico das companhias são utilizados como métricas para avaliar se o principal objetivo da governança corporativa está sendo atingido. Partindo desses pressupostos, objetivou-se com esta pesquisa verificar se o desempenho das empresas influencia na probabilidade de turnover da administração. Para tal, foram analisadas 87 empresas listadas no Novo Mercado da B3, por apresentarem maiores níveis de governança.

No que tange aos resultados da pesquisa, as variáveis "retorno das ações" e "retorno do patrimônio líquido" foram significativas, indicando que as empresas da amostra tendem a trocar seus gestores quando o resultado não é satisfatório. O resultado significativo e negativo dessas métricas é relevante, pois os preços das ações e o desempenho são, na literatura, as principais medidas de interesse dos acionistas, visto que mensuram a variabilidade dos ativos e como eles estão sendo salvaguardados. Portanto, é do interesse dos acionistas maiores ganhos com as ações, e, para tanto, é necessário que a empresa possua um bom desempenho. Este, por sua vez, está relacionado à administração; logo, quando a gestão não está sendo eficiente, justifica-se a troca.

Ressalta-se, no entanto, que a questão do turnover não está relacionada apenas ao desempenho do mercado financeiro, ou seja, existem características intrínsecas da firma que podem afetar a troca de gestores. Um exemplo disso é o fato de a propriedade ser familiar ou 
não. Para Lausten (2002), em empresas familiares, os gestores não são demitidos por causa de desempenho ruim, pois este é tratado coletivamente.

Este trabalho contribuiu com a literatura nacional, pois inovou em analisar apenas as empresas do Novo Mercado, visto que elas devem seguir padrões rigorosos de governança, a qual pode ser mensurada pelo turnover. Logo, este estudo indica para o mercado que as empresas listadas na B3 seguem os critérios de governança, conforme o esperado.Ademais, foram estimados os modelos LogitPooled, Efeitos Fixos e Aleatórios, para verificar qual deles melhor se adequava aos dados e, assim, obter os melhores resultados.

A relação entre governança corporativa e desempenho, com foco nos gestores, é amplamente estudada em economias desenvolvidas, como Estados Unidos, Dinamarca, Japão, Finlândia, Itália, entre outras. Dentre os principais estudos destes países, estão, respectivamente, Kaplan (1994a), Kang e Shivdasani (1995); Lausten (2002), Volpin (2002), Maury (2006) e Miyajima, Ogawa e Saito (2018). Este estudo mostra, sob a ótica de um país emergente, essa relação entre governança e desempenho medida pelo turnover.

Este trabalho traz implicações para a literatura brasileira, pois, apesar de a métrica turnover ser utilizada em diversos países desenvolvidos, no Brasil, os estudos são incipientes. Assim, esta pesquisa sugere a análise da rotatividade dos executivos como um parâmetro a ser considerado pelo mercado de capitais brasileiro; afinal, a substituição dos gestores pode indicar problemas de desempenho da companhia. Além disso, aponta para o mercado e para a literatura internacional que, em um segmento mais elevado de governança corporativa, mesmo de um país emergente, são adotadas medidas para melhorar os resultados corporativos.

Em relação às limitações encontradas nesta pesquisa, pode-se citar o fato de que algumas empresas não divulgaram, para todos os períodos analisados, informações sobre as movimentações dos cargos de seus principais gestores. Assim, a conclusão deste estudo foi baseada nas companhias que divulgaram as informações completas. Adicionalmente, não são disponibilizadas informações referentes ao motivo da destituição do cargo, não sendo possível uma análise mais aprofundada, visto que, como alguns CEOs ou presidentes do conselho permanecem no cargo por diversos anos consecutivos, algumas trocas podem ocorrer, por exemplo, por aposentadoria, não tendo qualquer relação com o desempenho.

Como sugestões para pesquisas futuras, destacam-se: (i) estimar modelos alternativos, considerando-se, separadamente, as variáveis ROA, ROE e Q-tobin e comparar o poder explicativo de tais modelos, tendo em vista que, neste estudo, especificamente, a análise final foi feita com base apenas na segunda variável; (ii) incluir outras proxies para avaliar o turnover, uma vez que, nesta pesquisa, tomou-se a decisão metodológica de empregar a proxy adotada 
por Volpin (2002), que pode se diferenciar daquelas empregadas em outros estudos; (iii) analisar se o turnover da administração é influenciado por outras variáveis, como, por exemplo, a concentração de direito a voto e o excesso de direito a voto; e (iv)realizar um comparativo entre países, objetivando identificar se a probabilidade de turnover da administração é fortemente influenciada pela bolsa de valores na qual a empresa está listada.

\section{REFERÊNCIAS}

AHMAD, S.; OMAR, R. Basic corporate governance models: a systematic review. International Journal of Law and Management, 2016.

ANDRADE, A.; ROSSETTI, J. P. Governança corporativa: fundamentos, desenvolvimento e tendências. São Paulo: Atlas, 2012.

ARMSTRONG, C. S.; GUAY, W. R.; WEBER, J. P. The role of information and financial reporting in corporate governance and debt contracting. Journal of Accounting and Economics, London, v. 50, p. 179-234, 2010.

B3. Segmentos de listagem. 2018. Disponível em http://www.b3.com.br/pt_br/. Acesso em: $01 \mathrm{dez} .2018$.

BHASA, M. P. Understanding the corporate governance quadrilateral. Corporate Governance: The International Journal of Business in Society, 2004.

BIANCHI, M. et al. A evolução e o perfil da governança corporativa no Brasil: um levantamento da produção científica do ENANPAD entre 1999 e 2008. ConTexto. Porto Alegre, v. 9, n. 15 (1. sem. 2009), p. 1-26, 2009.

BORNHOLDT, W. Governança na empresa familiar: implementação e prática. Bookman, 2000 .

BRICKLEY, J. A.; ZIMMERMAN, J. L. Corporate governance myths: comments on Armstrong, Guay and Weber. Journal of Accounting and Economics, v. 50, n. 2-3, p. 235$245,2010$.

CERNAT, L. The emerging european corporate governance model: anglo-saxon, continental, or still the century of diversity?. Journal of European Public Policy, v. 11, n. 1, p. 147-166, 2004.

COFFEE JUNIOR, J. C. Future as history: the prospects for global convergence in corporate governance and its implications. Columbia Law School Center for Law and Economic Studies Working Paper, New York, n. 144, p. 1-140, 1998.

COHEN, J. Statistical power analysis for the behavioral sciences. Academic Press, 2013.

CONYON, M. J.; FLOROU, A. Top executive dismissal, ownership and corporate performance. Accounting and Business Research, v. 32, n. 4, p. 209-225, 2002. 
CONYON, M. J.; HE, L. CEO turnover in China: the role of market-based and accounting performance measures. The European Journal of Finance, v. 20, n. 7-9, p. 657-680, 2014.

COOMBES, P.; WATSON, M. Corporate reform in the developing world. The McKinsey Quarterly, p. 89-89, 2001.

DAHYA, J.; MCCONNELL, J. J,; TRAVLOS, N. G. The Cadbury committee, corporate performance, and top management turnover. The Journal of Finance, v. 57, n. 1, p. 461-483, 2002.

DAVIS, G. F.; THOMPSON, T. A. A social movement perspective on corporate control. Administrative Science Quarterly, p. 141-173, 1994.

DENIS, D. J.; KRUSE, T. Managerial discipline and corporate restructuring following performance declines. Journal of Financial Economics, London, v. 55, n. 3, p. 391-424, 2000.

FALEYE, O. Classified boards, firm value, and managerial entrenchment. Journal of Financial Economics, v. 83, n. 2, p. 501-529, 2007.

FEE, E.; HADLOCK, C. J. Management turnover across the corporate hierarchy. Journal of Accounting and Economics, London, v. 37, n. 1, p. 3-33, 2004.

HAZARIKA, S.; KARPOFF, J. M., NAHATA, R. Internal corporate governance, CEO turnover, and earnings management. Journal of Financial Economics, London, v. 104, p. 44-69, april. 2012.

HITT, M. A.; IRELAND, R. D.; HOSKISSON, R. E. Strategic management cases: competitiveness and globalization. Cengage Learning, 2012.

HÖLMSTROM, B. Moral hazard and observability. The Bell Journal of Economics, Santa Monica, v. 10, n. 1, p. 74-91, 1979.

HOPT, K. J.; LEYENS, P. C. Board models in Europe-recent developments of internal corporate governance structures in Germany, the United Kingdom, France, and Italy. European Company and Financial Law Review, v. 1, n. 2, p. 135-168, 2004.

KANG, J.-K.; SHIVDASANI, A. Firm performance, corporate governance, and top executive turnover in Japan. Journal of Financial Economics, London, v. 38, n. 1, p. 29-58, 1995.

KAPLAN, S. N. Corporate governance and corporate performance: a comparison of Germany, Japan, and the US. Journal of Applied Corporate Finance, Chicago, v. 9, n. 4, p. 86-93, 1997.

KAPLAN, S. N. Top executive rewards and firm performance: a comparison of Japan and the United States. Journal of Political Economy, Chicago, v. 102, n. 3, p. 510-546, 1994a.

KAPLAN, S. N. Top executives, turnover, and firm performance in Germany. Journal of Law, Economics and Organization, Oxford, v. 10, n. 1, p. 142-159, 1994b. 
LA PORTA, R. et al. Legal determinants of external finance. The Journal of Finance, v. 52, n. 3, p. 1131-1150, 1997.

LA PORTA, R.; LOPEZ, F. de S.; SHLEIFER, A. Corporate ownership around the world. The Journal of Finance, v. 54, n. 2, p. 471-517, 1999.

LAUSTEN, M. CEO turnover, firm performance and corporate governance: empirical evidence on Danish firms. International Journal of Industrial Organization, v. 20, n. 3, p. 391-414, 2002.

MAASSEN, G. F. An international comparison of corporate governance models: a study on the formal independence and convergence of one-tier and two-tier corporate boards of directors in the Unites States of America, the United Kingdom and the Netherlands. Gregory Maassen, 1999.

MARTINS, G. de A.; THEÓPHILO, C. R. Metodologia da investigação científica para ciências sociais aplicadas. 2. ed. São Paulo: Atlas, 2009. 247 p.

MAURY, B. Corporate performance, corporate governance and top executive turnover in Finland. European Financial Management, Helsinki, v. 12, n. 2, p. 221-248, march. 2006.

MCCONNELL, J. J.; SERVAES, H. Additional evidence on equity ownership and corporate value. Journal of Financial Economics, London, v. 27, n. 2, p. 595-612, 1990.

MEIER, H. H.; MEIER, N. C. Corporate governance: an examination of US and european models. Corporate Ownership \& Control, v. 11, n. 2, p. 347-351, 2014.

MIYAJIMA, H.; OGAWA, R., SAITO, T. Changes in corporate governance and top executive turnover: the evidence from Japan. Journal of the Japanese and International Economies, v. 47, p. 17-31, march. 2018.

MOREIRAS, L. M. F.; TAMBOSI FILHO, E.; GARCIA, F. G. Dividendos e informação assimétrica: análise do novo mercado. Revista de Administração, São Paulo, v. 7, n. 4, p. 671-682, nov. 2010.

MURPHY, K. J. Executive compensation. Handbook of Labor Economics, v. 3, p. 24852563, june. 1999.

SCHULZE, W. S. et al. Agency relationships in family firms: theory and evidence.

Organization Science, v. 12, n. 2, p. 99-116, april. 2001.

SHLEIFER, A.; VISHNY, R.W. Large shareholders and corporate control. Journal of Political Economy, v. 95, p. 461-488, 1986.

SHLEIFER, A.; VISHNY, R. W. A survey of corporate governance. The Journal of Finance, v. 52, n. 2, p. 737-783, 1997.

SILVA, W. M. da; GRZYBOVSKI, D. Efeitos da governança corporativa e da performance empresarial sobre o turnover de executivos no Brasil: comparando empresas familiares e nãofamiliares. Revista de Administração Mackenzie, São Paulo, v. 7, n. 1, 2006. 
SILVEIRA, A. Di M. da. Governança corporativa e estrutura de propriedade: determinantes e relação com o desempenho das empresas no Brasil. 2006. 254 f. Tese (Doutorado em Administração) - Universidade de São Paulo, São Paulo, 2006.

VERGARA, S. C. Projetos e relatórios de pesquisa em administração. 15. ed. São Paulo: Atlas, 2014. 94 p.

VIEIRA, C. A. M.; MARTINS, O. S. Influência da estrutura do conselho de administração e do controle corporativo no turnover do CEO das empresas abertas no Brasil. Revista Contemporânea de Contabilidade, Florianópolis, v. 15, n. 34, p. 181-201, mar. 2018.

VOLPIN, P. F. Governance with poor investor protection: evidence from top executive turnover in Italy. Journal of Financial Economics, London, v. 64, n. 1, p. 61-90, march. 2002.

WARNER, J. B.; WATTS, R.; WRUCK, K. H. Stock prices and top management changes. Journal of Financial Economics, London, v. 20, n. 1-2, p. 461-492, 1988.

WEISBACH, M. S. Outside directors and CEO turnover. Journal of Financial Economics, London, v. 20, p. 431-460, 1988.

WOOLDRIDGE, J. M. Econometric analysis of cross section and panel data. MIT Press, 2010.

\section{DADOS DOS AUTORES}

Nome: Bárbara Siqueira da Silva

E-mail: barbara.s_silva@hotmail.com

Curriculum Lattes: http://lattes.cnpq.br/1324183694562147

Mestrado em Contabilidade Financeira pela Universidade Federal de Minas Gerais (UFMG). Especialização em Contabilidade Pública e Auditoria pela Faculdade de Venda Nova do Imigrante (FAVENI) e graduação em Ciências Contábeis pela UFMG.

Nome: Danielle Gonçalves Silva

E-mail: usadanny@ hotmail.com

Curriculum Lattes: http://lattes.cnpq.br/5251557527779393

Mestrado em Contabilidade Financeira pela Universidade Federal de Minas Gerais (UFMG). MBA em Contabilidade e Finanças pelo Centro Universitário de Belo Horizonte (UniBH).

Graduação em Ciências Contábeis pela Pontifícia Universidade Católica de Minas Gerais (PUC-MG).

Nome: Bruna Camargos Avelino

E-mail: bcavelino@gmail.com

Curriculum Lattes: http://lattes.cnpq.br/9268916643690315

Doutora em Controladoria e Contabilidade pela Faculdade de Economia, Administração e Contabilidade da Universidade de São Paulo (FEA/USP). Professora Adjunta do Departamento de Ciências Contábeis da Universidade Federal de Minas Gerais (UFMG). 
Nome: Valéria Gama Fully Bressan

E-mail: valeria.fully@gmail.com

Curriculum Lattes: http://lattes.cnpq.br/0249079418500669

Pós-doutorado; doutorado; mestrado em Economia Aplicada pela Universidade Federal de Viçosa e graduação em Administração com habilitação em Cooperativas pela Universidade Federal de Viçosa. Atualmente é professora do Departamento de Ciências Contábeis e atual Coordenadora do Centro de Pós-graduação e Pesquisas em Controladoria e Contabilidade (CEPCON) da FACE/UFMG. 